\title{
دور التربية الإسلامية في مواجهة الشُبهات الفكرية المعاصرة
}

\author{
آسيا بنت حسين محمد منشط آنش

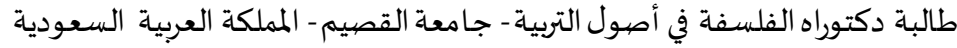 \\ phd.ah40@gmail.com
}

ما يدور في فلك الحياة المعاصرة من الأحداث وما يستحثه التقدم العلمي من التفات الناس إلى الغرب، ذلك الذي ولد لدى الكثير من الأفراد

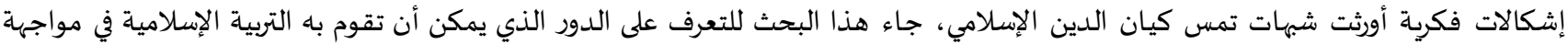

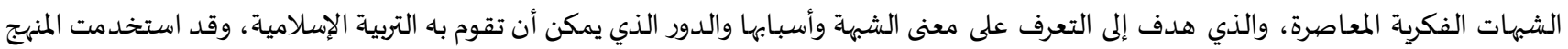

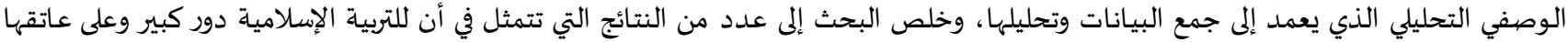

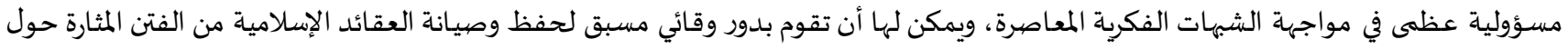

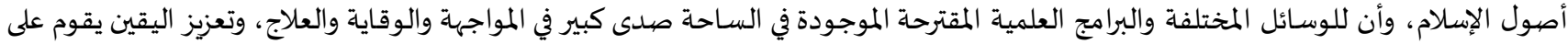
التربية الإيمانية التي ينبغي على كل مربي أن يولي العناية بها.

الكلمات المفتاحية: التربية الإسلامية؛ الشبهات.

\section{(ब) (1)}

المقدمة:

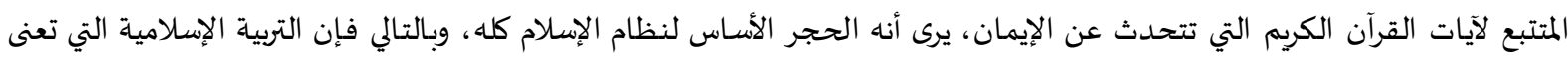

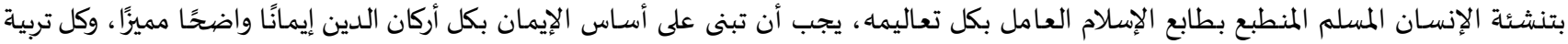

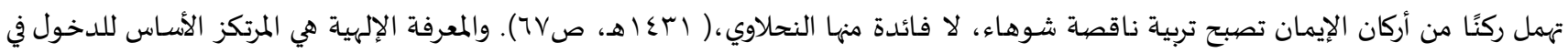

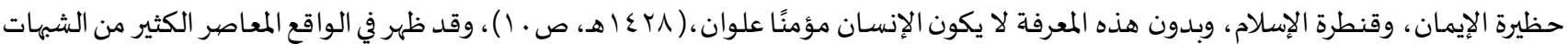

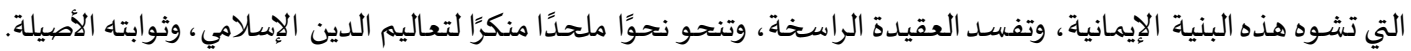

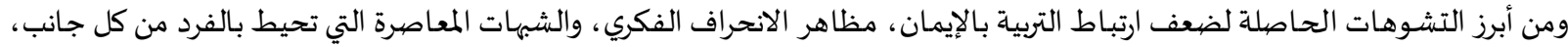

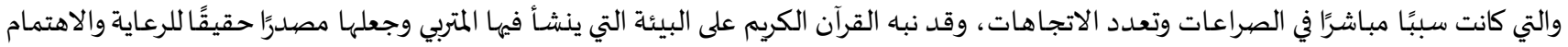

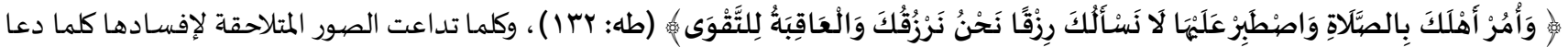

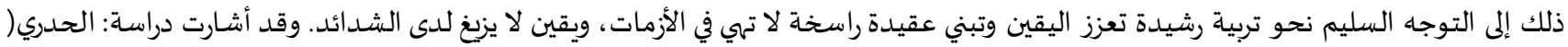

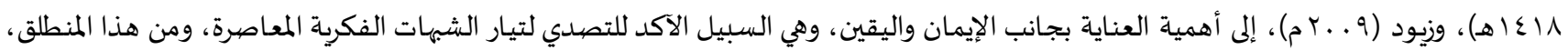

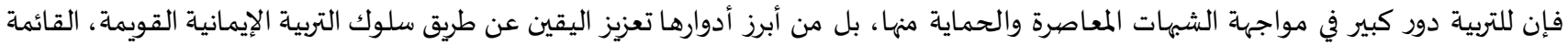

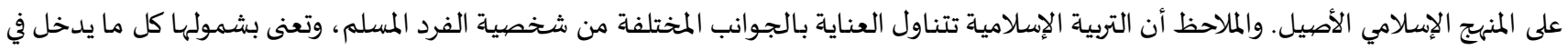

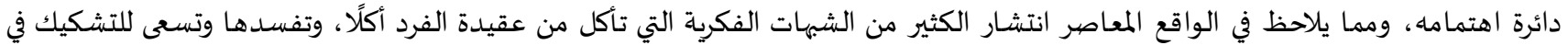

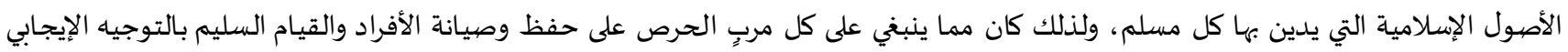

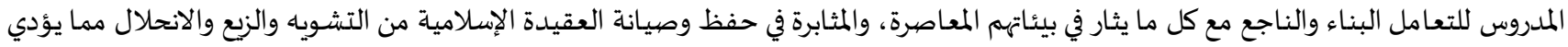

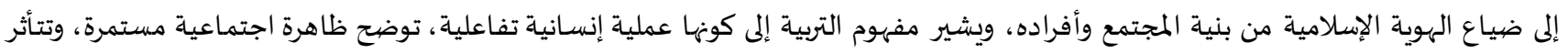

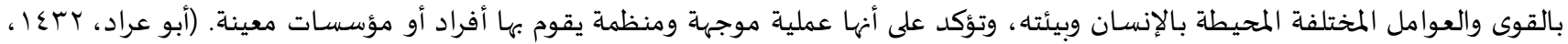


وتهتم التربية الإسلامية بالكيان الإنساني كله، وتجعل من التربية الإيمانية أساسها الأول، ومنطلقها الرئيس في بناء شخصية الإنسان المسلم،

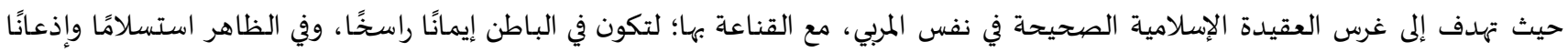

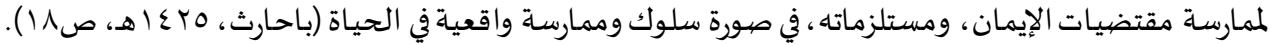

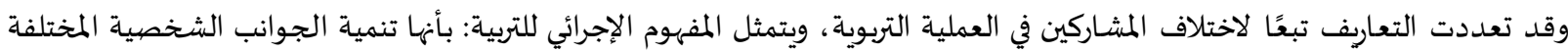

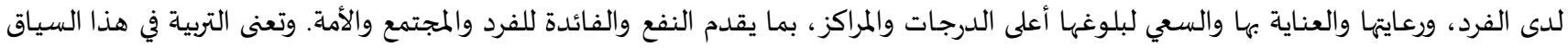

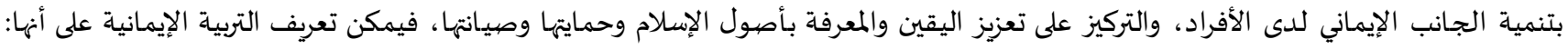

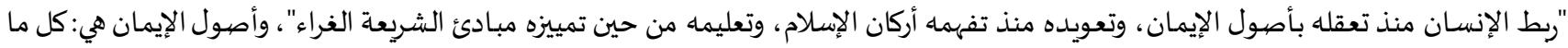

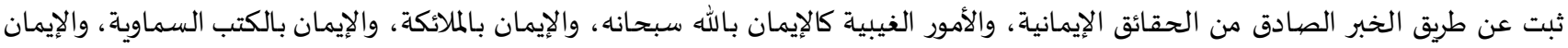

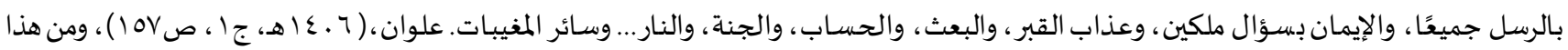

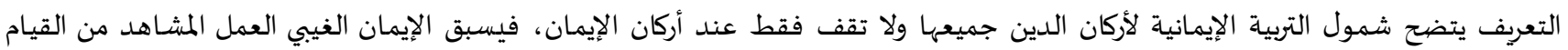

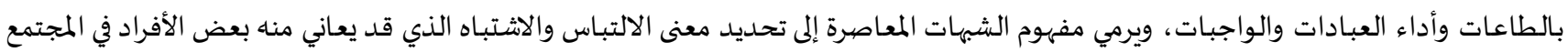

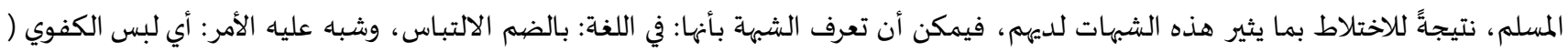

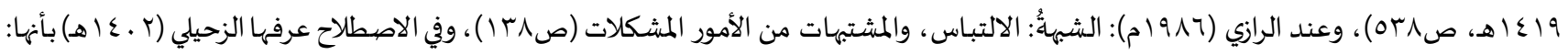

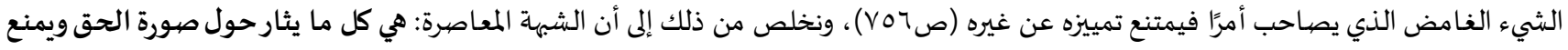

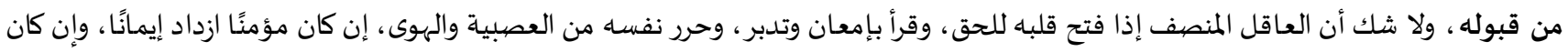

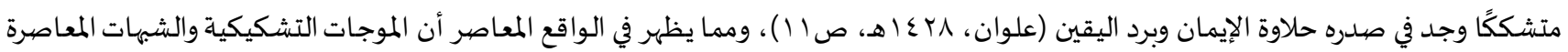

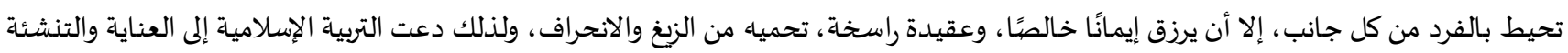

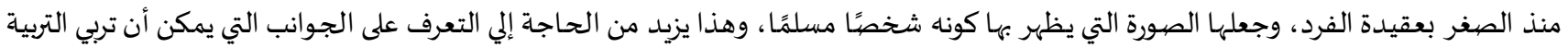

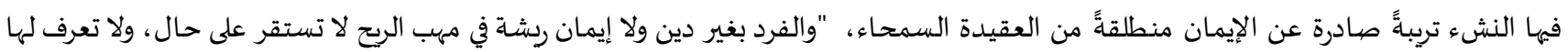

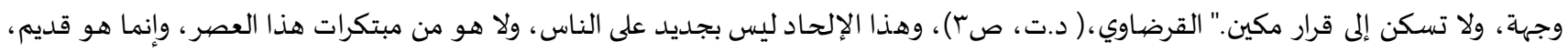

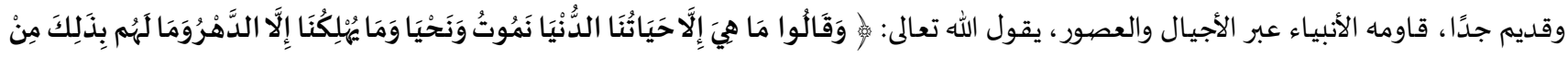

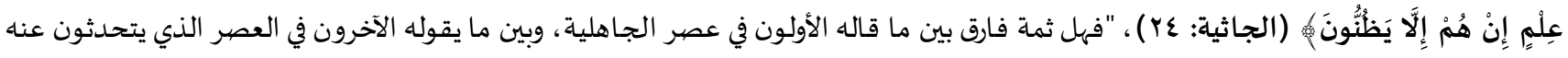

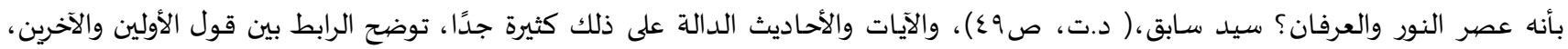

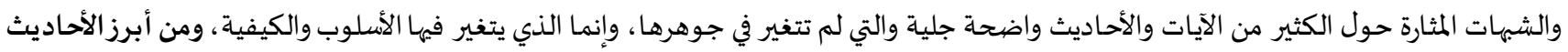

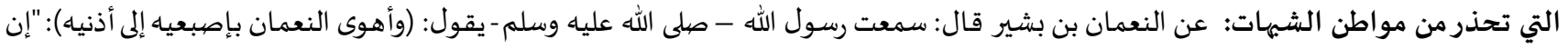

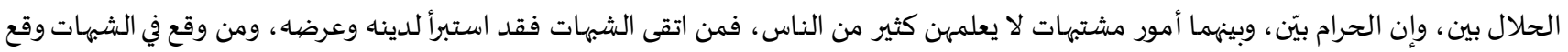

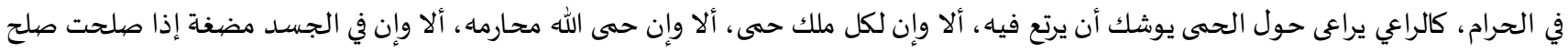

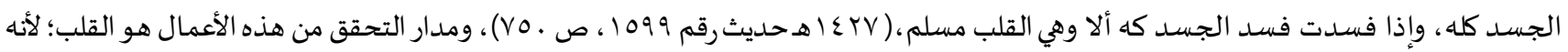

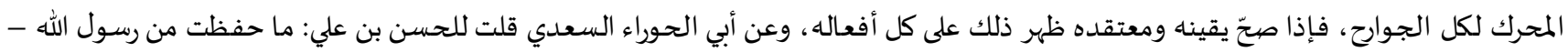

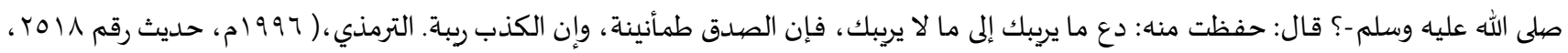

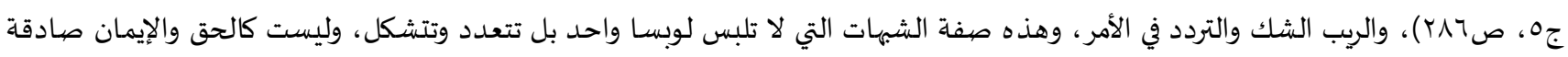

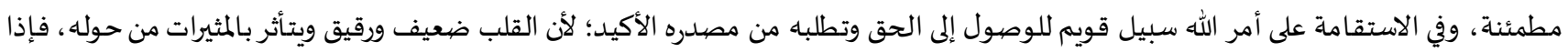

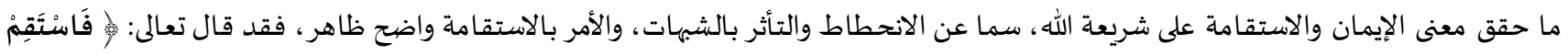

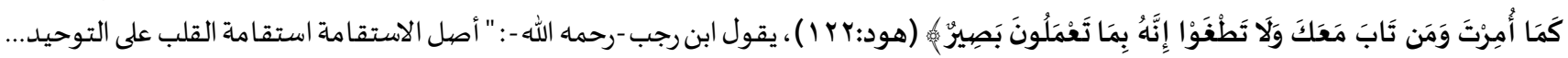

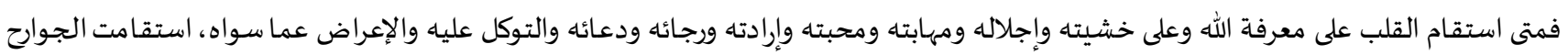

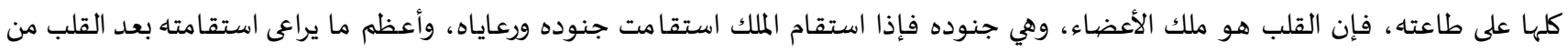

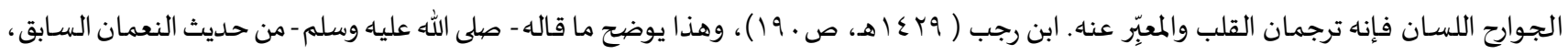

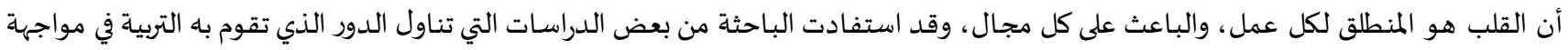

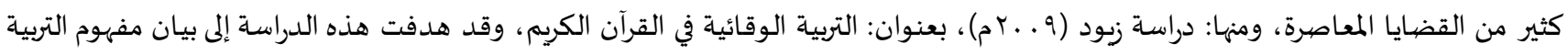

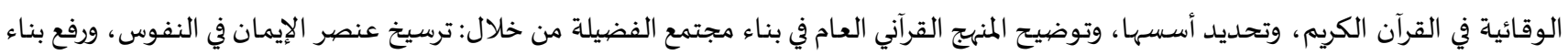

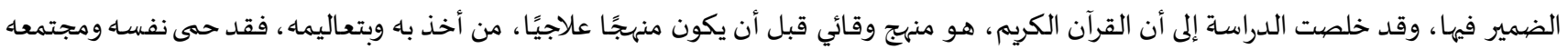




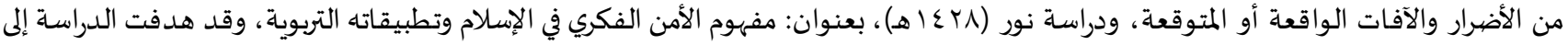

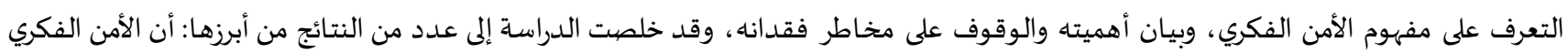

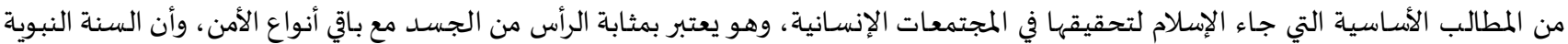

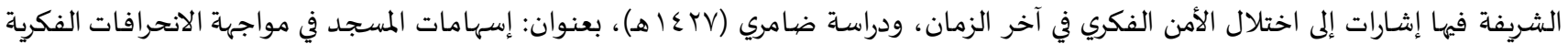

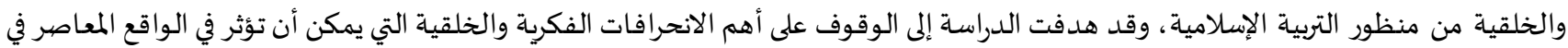

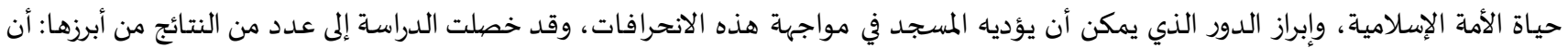

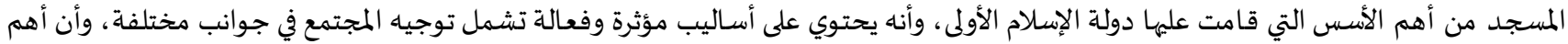

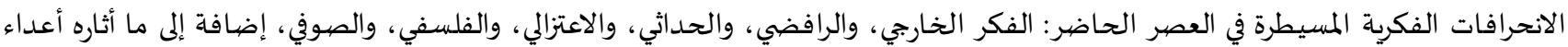

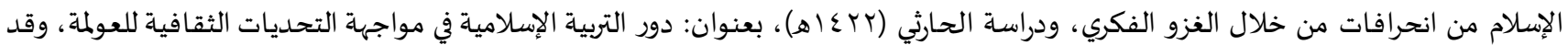

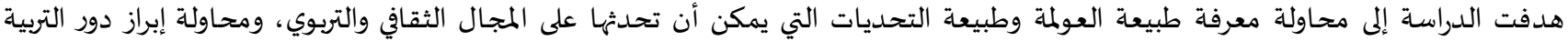

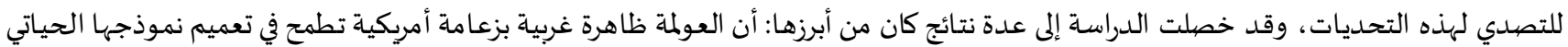

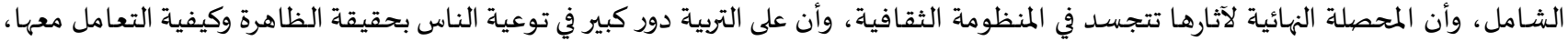

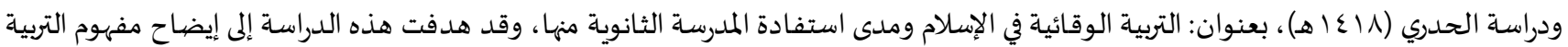

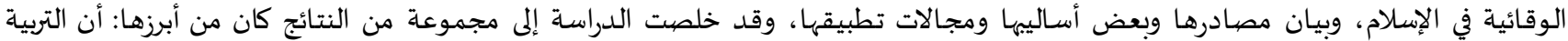

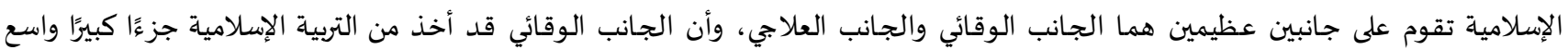

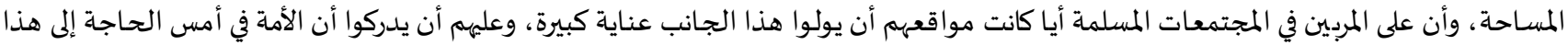

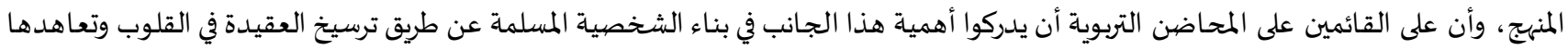
كل حين، ومن خلال استعراض الدراسات السابقة يتضح وجود أوجه اتفاق واختلاف مع الدراسة الحالية، ولا يخفى الجهود العظيمة المبذولة

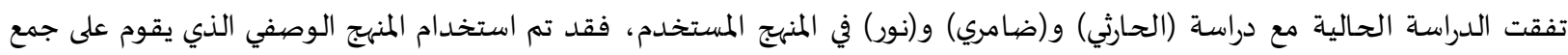
البيانات والمعلومات وتحليلها وتفسيرها، واختلفت مع دراسة (الحدري) و(زيود) في المنهج المستخدم.

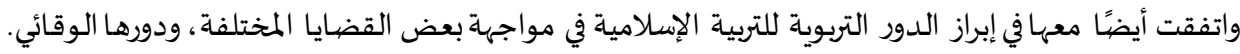
واختلفت عن الدراسات السابقة في كونها تناولت دور التربية في مواجهة الشبهات الفكرية المعاصرة. وتميزت عن باقي الدراسات باقتراح برنامج عملي لتطبيق الدور التربوي للتربية.

وقد استفادت الباحثة كثيرا من طريقة العرض والتبيين التي سلكوها، وأخذت بالتوصيات التبات التي كانت تدور حول الاهتمام بمعالجة القضايا الفكرية والمعاصرة، وقد استفادت أيضًا منها منهجية البحث وكتابة الإطار النظري، والمراجع والمصادر المختلفة المانة.

مشكلة البحث:

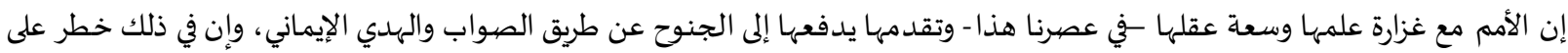

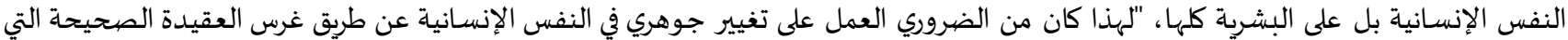

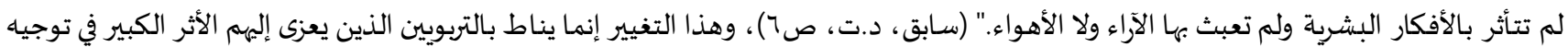

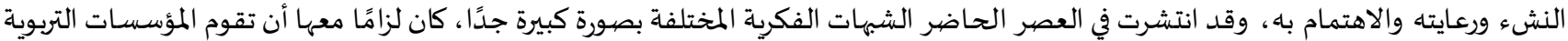

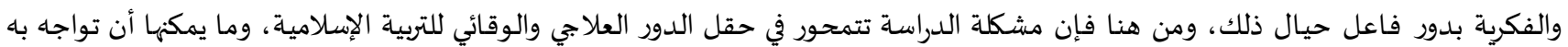
الشهات الفكرية المعاصرة، وتتمثل مشكلة هذه الدراسة في السؤال الرئيسي التالي:

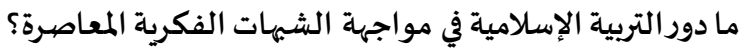

$$
\begin{aligned}
& \text { وتجيب هذه الدراسة عن عدة تساؤلات فرعية ناتجة عن السؤال الرئيس: } \\
& \text { ما المقصود بالتربية والشبهات الفكرية المعاصرة؟ فرعات } \\
& \text { ما أسباب ظهور وتأثر الأفراد بالشبهات الفكرية المعاصرة؟ }
\end{aligned}
$$

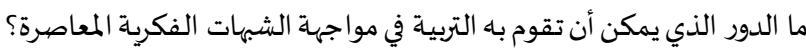


مما لاشك فياه أن المجتمع المسلم بحاجة مستمرة لإبراز الدور التربوي الذي تحث عليه الشريعة الإسلامية، وتسعى من خلاله لحل المشكلات

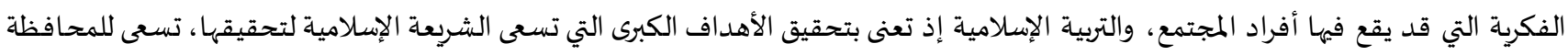

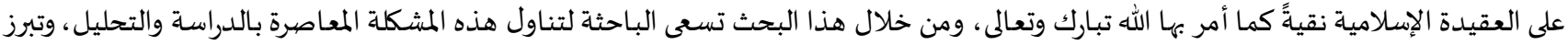
أهمية هذا البحث في المفردات التالية: تنبع أهمية البحث من كونها محاولة صادقة في المحافظة على العقيدة الإسلامية السمحة في نفوس الأفراد، ورعايتها من الشبهات أو الأفكار التي

إثراء المكتبات الإسلامية بهذه النوعية من البحوث التي تساعد على التعرف على الدور التربوي في مواجهة الشبهات الفكرية المعاصرة. إبراز أهمية التربية الإسلامية في تعاملها مع الشبهات الفكرية، وزيادة الوعي بها ومعرفة طرق الرد والحوار. إبراز أهم السبل التي تعين على حفظ الأفراد وصيانة عقائدهم وإيمانهم من الشبهات الفكرية المعاصرة. يفيد المربين بالمعلومات التي تعزز اليقين والجوانب الإيمانية لديهم ولدى الأفراد، وتسهم في الحث على توظيف التربية الإسلامية في مواجهة الشبهات والانحرافات الفكرية المعاصرة. أشـارت الدراسـات الحدري( 11 إ اهـ)، وزيود( ( . . بم)، إلى أهمية التركيز على الجوانب الوقائية من خلال توظيف التربية الإسلامية في ذلك. حاجة الميدان التربوي والثقافي إلى الوقاية من الشههات المثارة ضد الإسلام، ومعرفة كيفية التعامل معها. يفيد هذا البحث بإذن الله المؤسسات التربوية والتعليمية في المجتمع.

مصطلحـات البحث:

(. دور: عرفه الجرجاني ب:" الدور: هو توقف الشيء على ما يتوقف عليه، ويسهى الدور المصرح كما يتوقف أ على ب" (صץ 9).

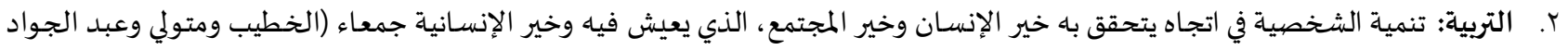

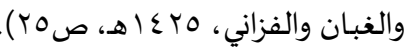

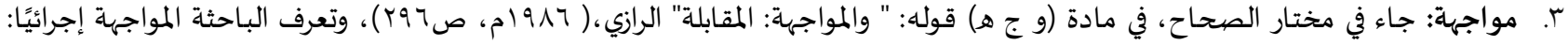

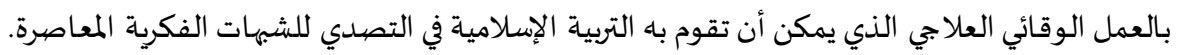

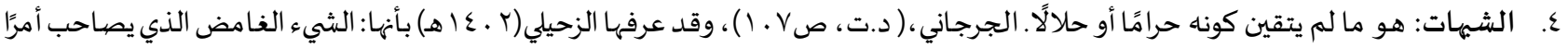

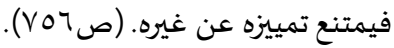
0. الشبهات الفكرية المعاصرة: يمكن تعريفها إجرائيًا: بالموضيوعات الغامضية التي تثار حول أصول الإسلام، والتي تسعى لإفسـاد عقيدة التوحيد والتشكيك في اليقين. إجراءات البتحث:

أسباب ظهوروتأثر الافراد بالشبهات الفكرية المعاصرة تعدد الأسباب وتتنوع، ومنها القريب الظاهر وبعضهيها البعيد المتخفي، ولاشك أن سهولة الوصيهول إلى الى مواطن الشبهات مما دعا إلى انتشارها،

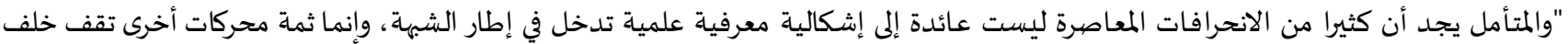

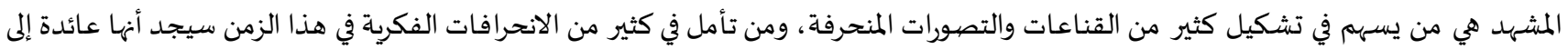

هينمة النموذج الثقافي الأجنبي.

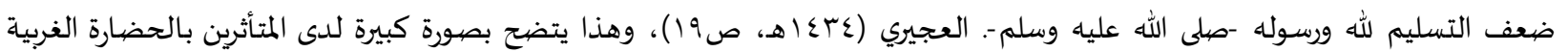
والمنغمسين فهها سواء بالعيش أو المتابعة، وكثيرًا ما تبث هذه الشبهات من خلال المشاهد والأفلام، وقد أشار المهندس أحمد حسن إلى مدى تأثير

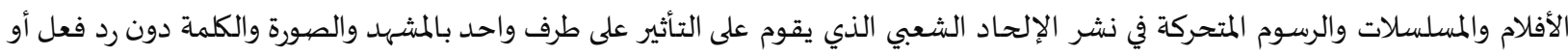

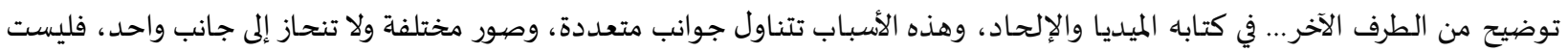

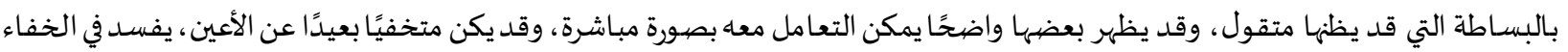
دون الانتباه إليه إلا بعد الوقوع في الشبهة، ويمكن توضيح ذلك من خلال المفردات التالية: 
النشأة في بيئة خالية من الآداب والقيم الإسلامياة ومبـادئ هـايتاه، فلا يتلقى فيها الفرد ما يقيم سلوكه أو يوجه عقيدته ، فتضعف الإيمانيات المنتشرة حوله ، وبالتالي فأقل شبهة تمس ذهناه وقلبها ، ويرجع ذلك إلى ضعف المتابعة الإيمانية من الوالدين. الاتصال بالرفاق السيئين فاسـي العقيدة، الذين يتأثر بهم الفرد بالأسلوب المغري، واللسـان البارع، والتأثير بالتفاعل المباشر معهم، والمزبي الفطن يحرص على تربية أبناءه على العقيدة الراسخة التي توجهاه وتنفره من أصدقاء السـوء. القراءة في بعض الشبهات التي تمس القلب بسـوء، من مؤلفات بعض الملحدين أو الفلاسفة، أو يتابع بعض منتجاتهم الإعلامية أيًا كان نوعها، وهذه أثرها كبير جـدًا من خلال التروبت لشبهات بطريقة براقة ، ومادة ملفتـة، أو يخـوض في "وسـائل التواصل الاجتماعي" مع بعض الحسابات التي تروج الشبهات، فيتأثر لعدم امتلاكه لأدوات النقد والعلم الشرعي الذي ينقض الشبهة ويوجـه التعامل معها. الإشكالات والأسئلة المتداولة التي تنز بالفكر عن طريق استقامته، ويدعمها بعض المواقف السلبية التي من شـأنها أن تعزز هذه الأسئلة دون إجابات واضحة موجهة لها. كذلك بعض المشكلات التي تحيط بالشخص، والضغوطات النفسية التي لم يستطع التخلص منها، والتي تؤدي إلى وقوعاه في الشبهة، والسؤالات

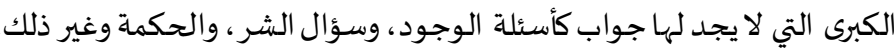
ومن أسباهها أيضًا: أن تغلب الشهوات على نفس الفرد، فتريه أن المصلحة في إباحتها، وأن تحريم الشارع لها خال من كل حكمة، فيخرج من هذا

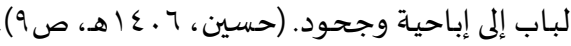
بعض المناهج والمقررات التي ترجمت عنها معظم المناهج التعليمية في البلاد العربية والإسلامية، أقيمت على أساس من الكفر والإلحاد، واعتبار

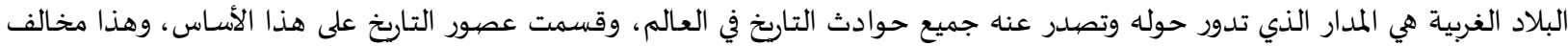

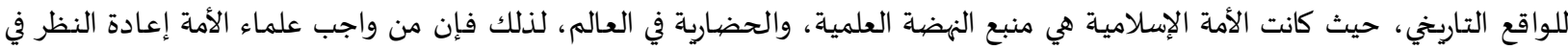

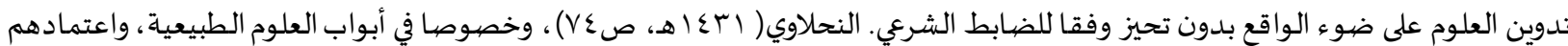

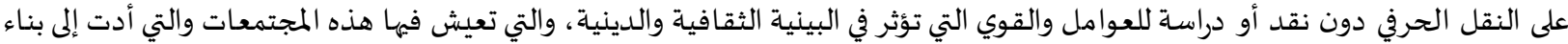

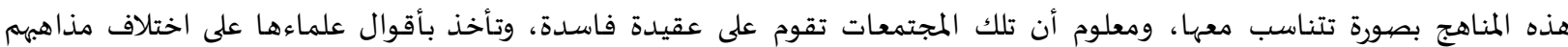
ومعتقداتهم، وهذا ينعكس على المقررات، والمناهج. وقد تصنف هذه الأسباب إلى قسمين: داخلية وخارجية.

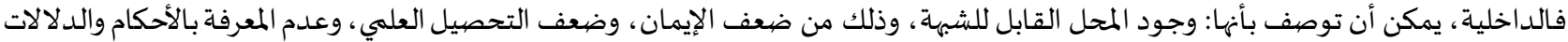

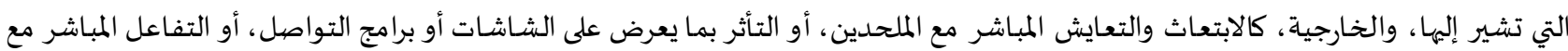
الشهية مع قلة الخبرة وضعف الإيمان.

دورالتربية في مواجهة الشههات الفكرية المعاصرة

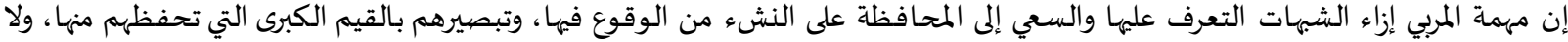

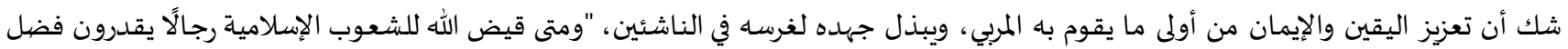

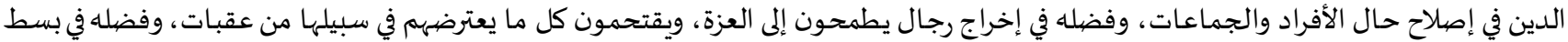

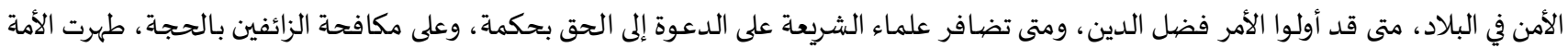

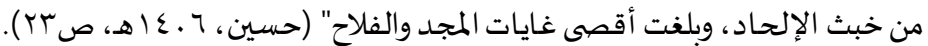

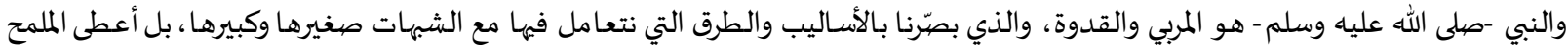

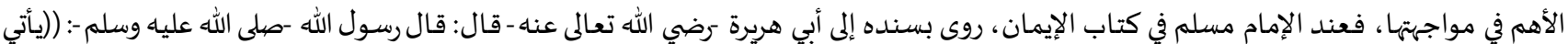

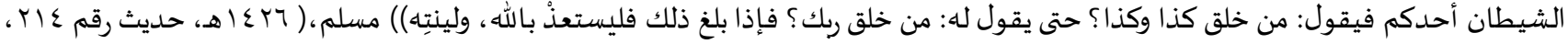

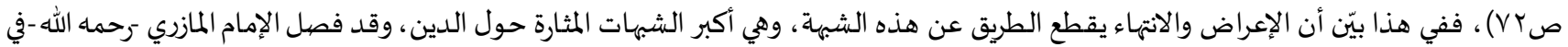

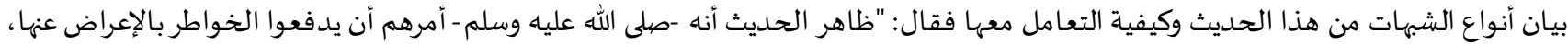

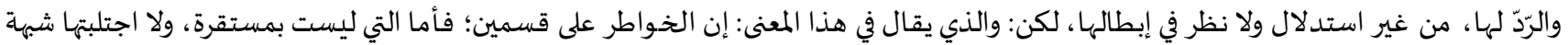

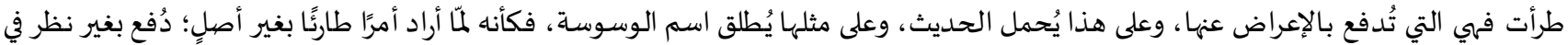

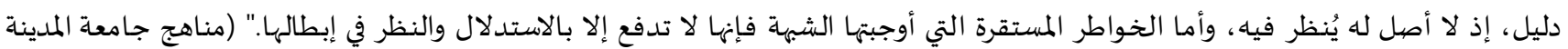




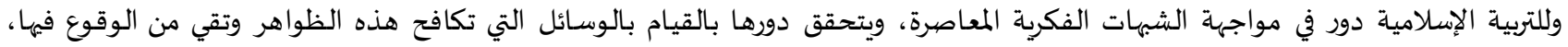

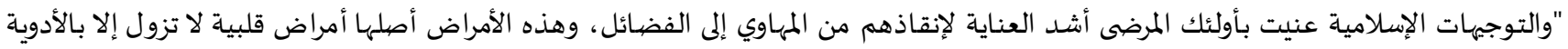

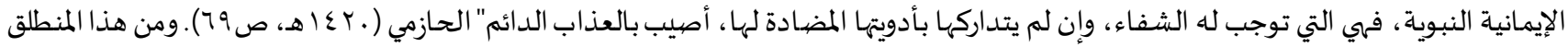

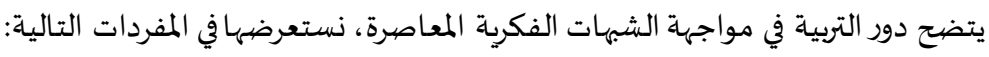

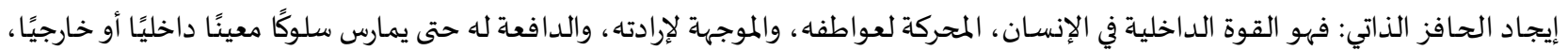

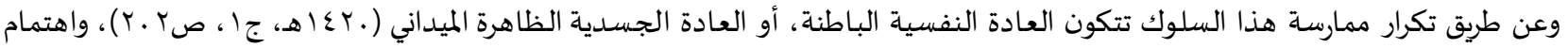

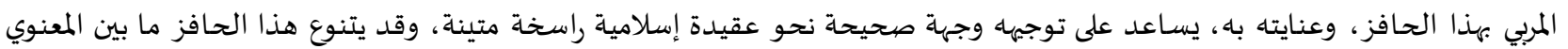

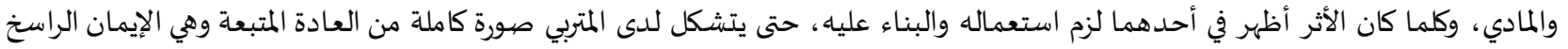
النافذ في كل جانب. الإيمان بالله يولد قوة فوق كل القوى، فهو يقبض على زمام العقل بالحق والبرهان من الله، ويقبض على ناصية القلب بعاطفة محبة الله وابتغاء رضاه والثقة بحكمته، ويقبض على زمام النفس بعاملي الخوف من عقاب الله والطمع بثوابه العظيم، وبناء الإيمان إنما يكون بالتربية التهاية الإيمانية

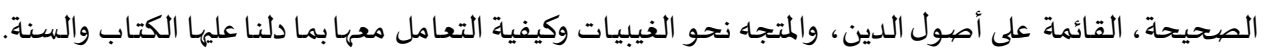

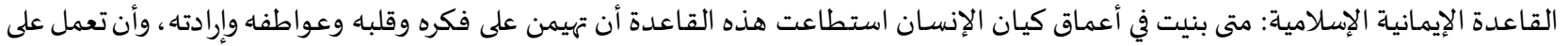

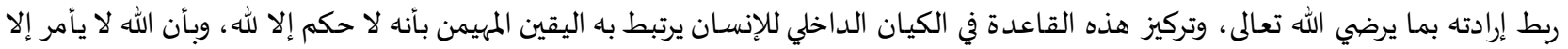

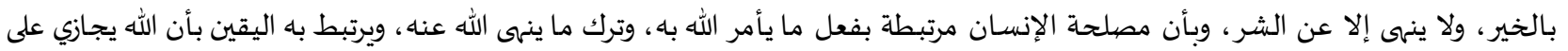

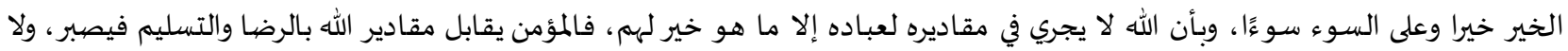

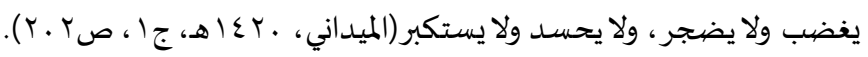

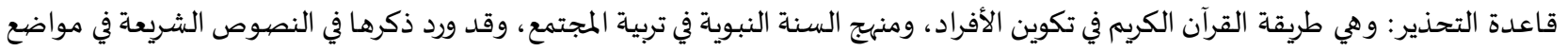

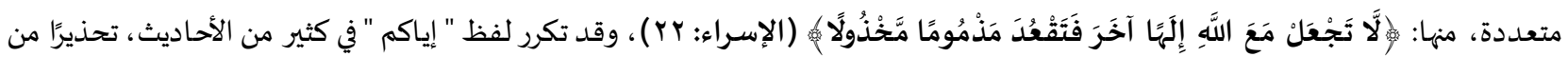

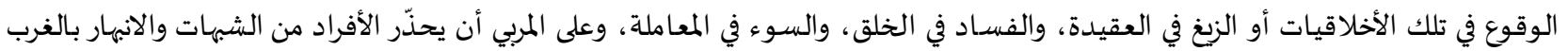

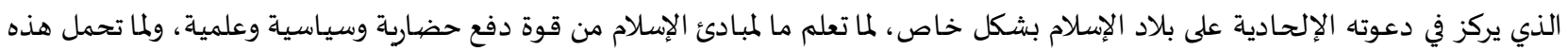

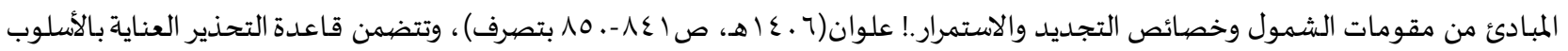

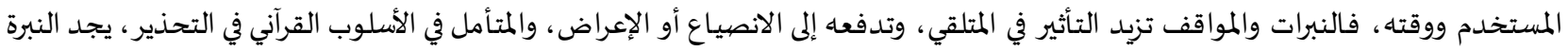
القوية والصارمة التي توضح مدى سوء هذا العمل.

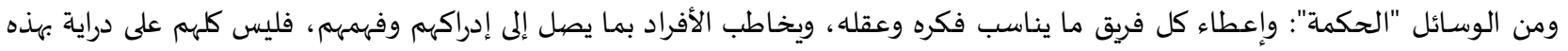

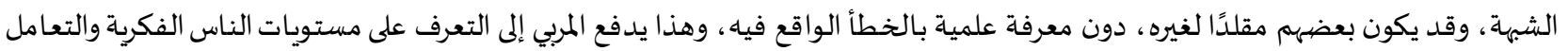

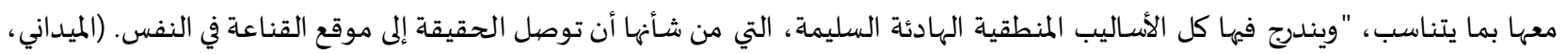

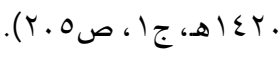

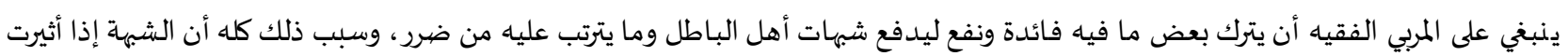

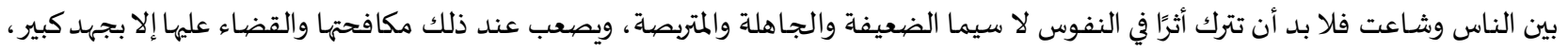

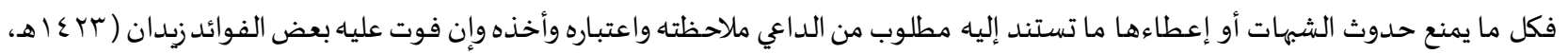

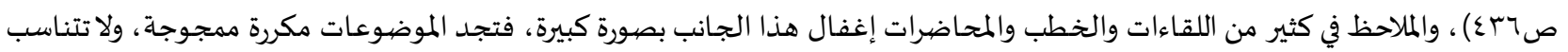

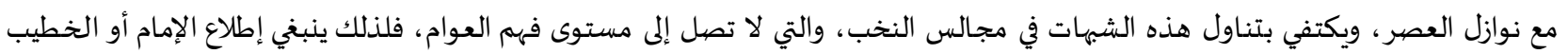

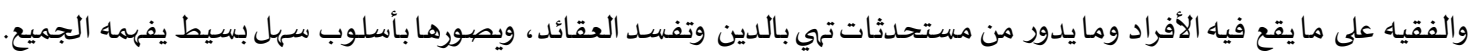

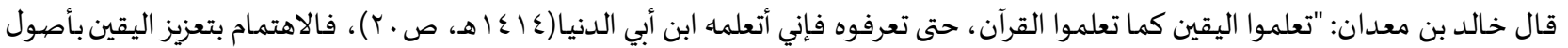

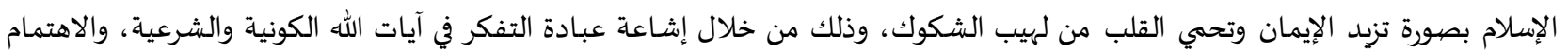

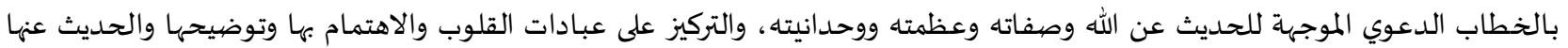

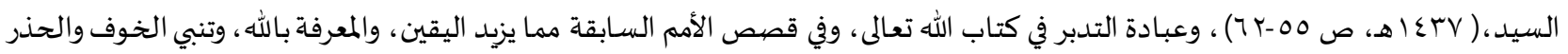

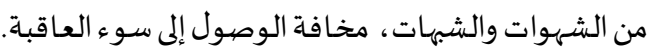

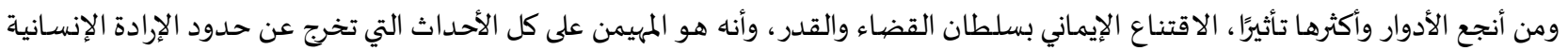

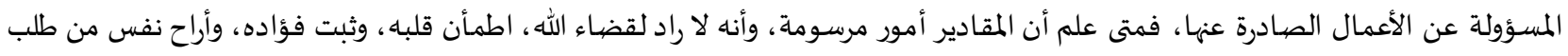




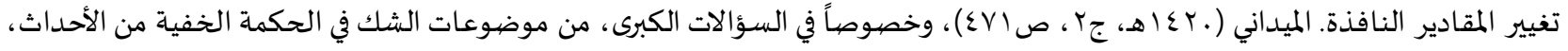

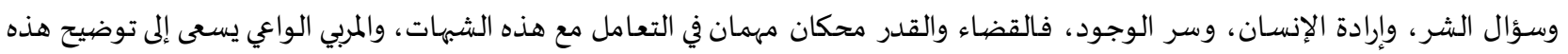

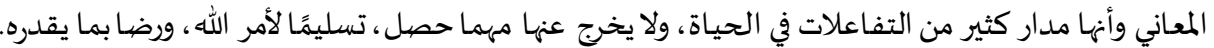

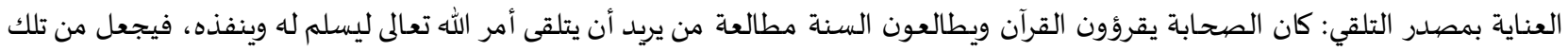

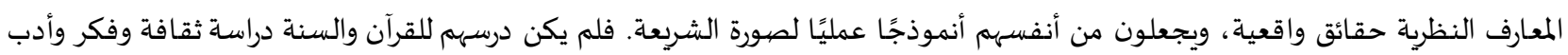

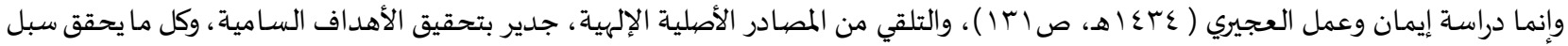

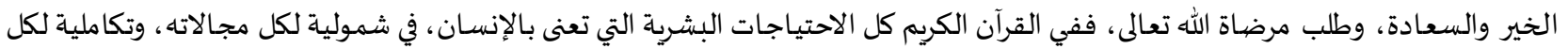

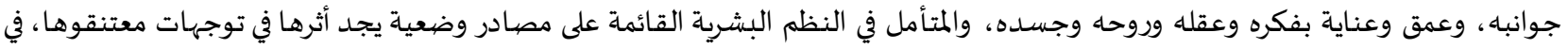

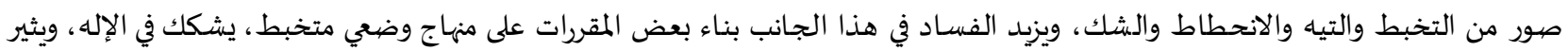
الشبهات.

العمل بمقتضى العلم: العناية بإكساب الفرد مهارة التفكير العلمي البعيد عن الخرافات والشطحات التي تستنزف الجهد والدين دون فائئدة.

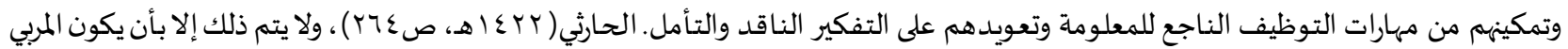

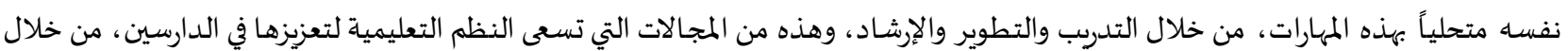

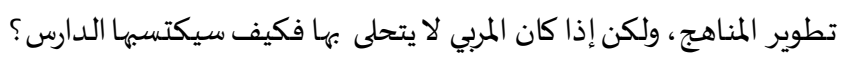

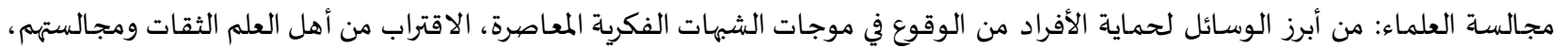

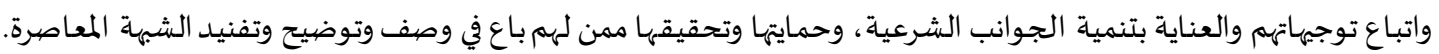

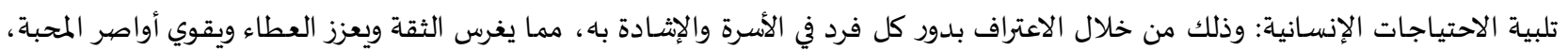

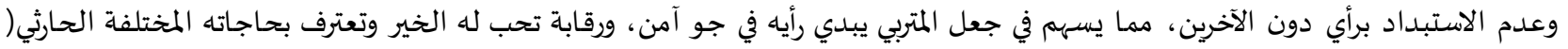

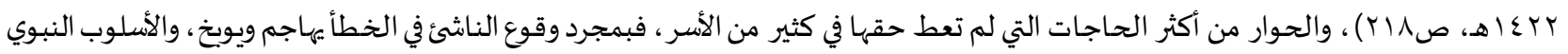

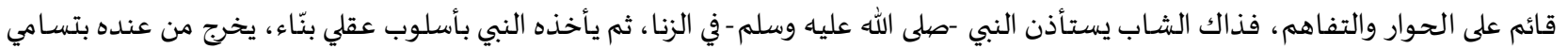
وترفع عن تلك الدنايا.

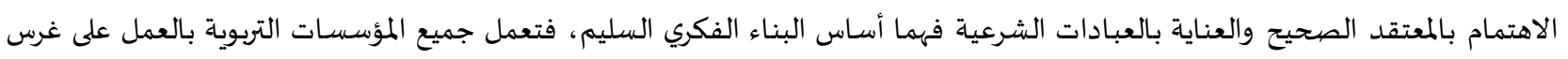

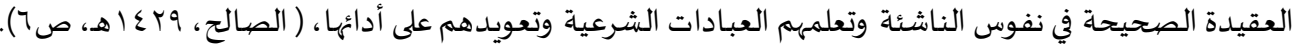

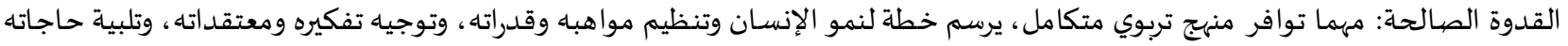

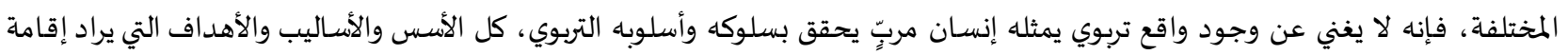

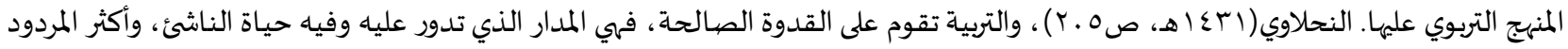

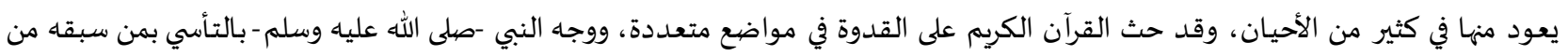

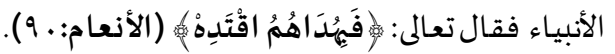

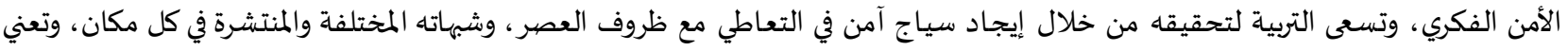

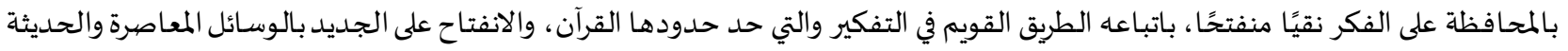

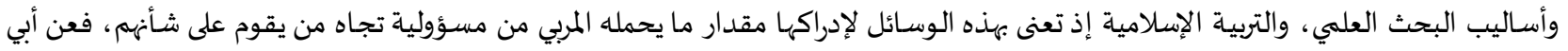

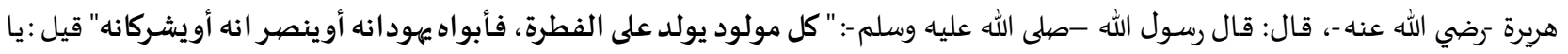

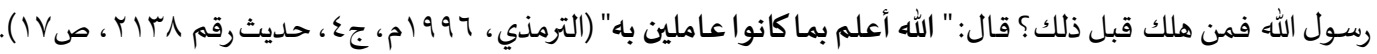

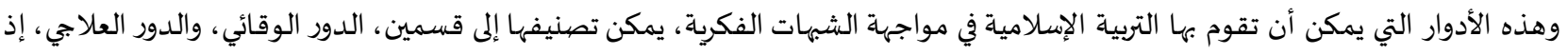

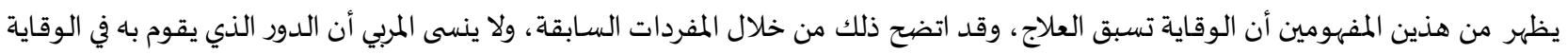

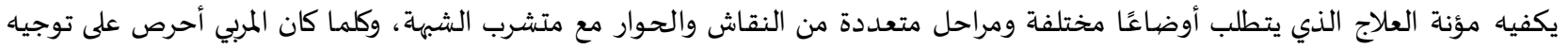

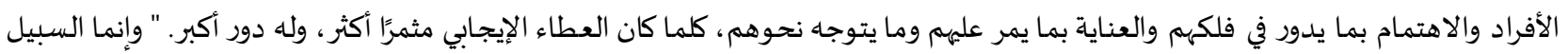

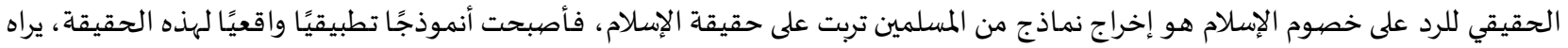

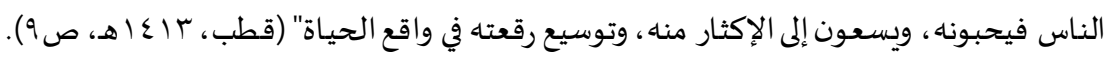


وحتى تحقق التربية الإسلامية الدور الذي تسعى إليه، يمكن اتباع بعض الاستراتيجيات الناجعة في تحقيق ذلك من الوقاية والعلاج للوقف أمام الشبهات الفكرية ، ومنها:

لفت نظر الفرد إلى الآيات الكونية، لغرس عقيدة التوحيد في النفوس. ويمكن تطبيق ذلك من خلال: عرض المواد الإعلامية المتخصصية وربطها

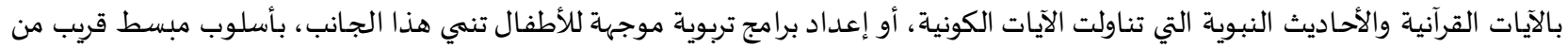

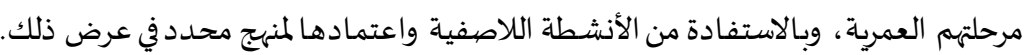
استغلال أسئلة الأطفال البريئة التي تحركها في الغالب نداءات الفطرة؛ لغرس مفاهيم التوحيد الكامل والشـامل بصهورة صحيحة وهادئة. استغلال وسائل الترفياء، وخاصة ذات الطابع الإعلامي؛ لتكون منابر دعوية إسلامية تسهم في تغذية العقيدة، من خلال: إقامة المنافسات في إعداد البحوث، وتوظيف التقنيات الحديثة في دراسة القيم الإيمانية ونشرها في الأوساط المتأثرة بالشبهات، وذلك بتوظيف المحتوى الملائم الذي يجذب إنبات الانتباه. إعداد برمجيات تعليمياة تربوية توظف أهم الأفكار التي تعزز اليقين، وتدعم السياج الإيماني ونشرها في -وسائل التواصل الاجتماعي-، أو في المجالات التي يمكن أن تحقق فائدة منها. إعداد برنامج علمي أو دورة تطبيقية تتلائم مع مستويات التعليم العام، وتكليف بعض المنسـوبين - من ذوي الكفاءة - لهذه الجهات بتقديمها في المدارس والمحاضين التربوية. إقامة البرامج والدورات -أمثال صناعة المحاور -، التي تعزز اليقين، وتذب عن حياض الإسلام، بطريقة مبسطة تتلائم مع كافة الطبقات الفكرية في المجتمع.

يتأثر البعض خصوصًا -ـالمراهقين - بمشـاهير الإعلام، يمكن الاستفادة منهم بتوضيح سبل الوقاية من الشبهات المعاصرة، بأسـاليب إعلامية جاذبة ، تستقطب كافة المراحل العمرية والفكرية. ومن المشـاريع في التربية قديمًا: "مشروع العامي الموحد" وهي مرحلة تأهيلية لما بعدها حيث يستطيع من ألم بالمعلومات البسيطة فيها، أن يواصل

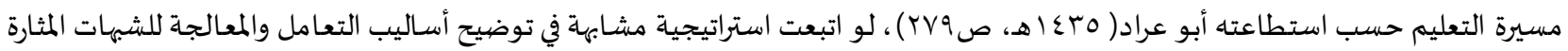

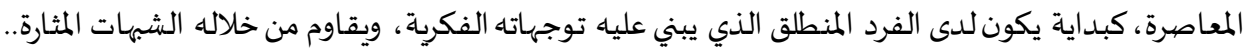
إن الأفراد المسلمين بحاجة ماسة إلى تحصين العقول، وتبصيرهم بوسيلة التعامل مع متغيرات هذا العصر وتحدياته، و" إن الإيمان بالله وباليوم

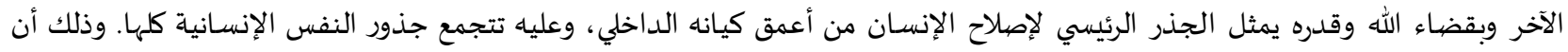

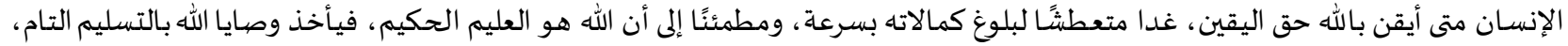

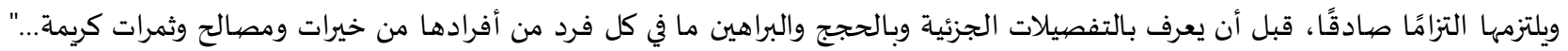

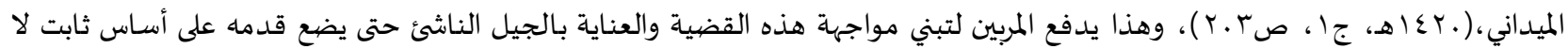

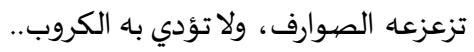

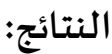

الحمد الله الذي وفق وأعان على إعداد هذا البحث الذي تناول جانب مهم في الواقع المعاصر ، وقد خلصت الباحثة في ذلك إلى عدد من النتائج: للتربية الإسلامية دور كبير وعلى عاتقها مسؤولية عظمى في مواجهة الشبهات الفكرية المعاصرة. يمكن للتربية الإسلامية أن تقوم بدور وقائي مسبق لحفظ وصيانة العقائد الإسلامية من الفتن المثارة حول أصبول الإسلام. الدور العلاجي للتربية الإسلامية يتضمن القيام بعدد من البرامج والدورات وتوظيف وسائل الإعلام والترفيه المختلفة في تحقيق هذا الدور في المواجهة. حاجة الأمة الإسلامية في كل مؤسساتها على وجه العموم، ومؤسساتها التربوية خصوصًا إلى الدفاع والمواجهة، والوقاية خير من العلاج. أن الوسائل المختلفة والبرامج العلمية المقترحة الموجودة في الساحة حاليًا تركت صدى كبير في المواجهة والوقاية والعلاج، وهذا البحث تطمح إلى إيجاد برامج مشابهة تعنى بهذا المجال. المؤسسات التربوية لها دور كبير في تفعيل الدور التربوي في مواجهة الشبهات الفكرية المعاصرة. ضرورة توثيق التفاعل الإيجابي مع برامج الإعلام لتنقيح الإصيدارات المختلفة. تعزيز اليقين يقوم على التربية الإيمانية التي ينبغي على كل مربي أن يولي العناية بها دراسةًً وتطبيقًا وتطويرًا. 
وبعد الوصول لعدد من النتائج في هذا البحث، توصي الباحثة بما يلي:

على الجهات التربوية الاستفادة من التوجهات الإعلامية المعاصرة وتوظيفها في إبراز دور التربية في مواجهة الشبهات الفكرية المعاصرة.

يمكن للمربين استحداث أسـاليب مختلفة ضمن البرامج اللاصفية لبناء اليقين وتعزيزه، وفقًا للعلم الشرعي الصحيح.

أن يحرص المربون على التأصيل الشرعي، والفكري والاهتمام بعوامل انتشار الشبهات المثارة، وإجادة التعامل معها وفقا للمنظور الإسلامي الصحيح. الاهتمام بالتطبيقات الوقائية والعلاجية التي تسهم في تحقيق الأمن الفكري.

ا. الترمذي، أبي عيسى محمد بن عيسى، (79 99 ام) الجامع الكبير للإمام الحافظ أبي عيسى محمد بن عيسى الترمذي، تحقيق: بشـار عواد معروف.

$$
\text { بيروت: دار الغرب الإسلامي }
$$

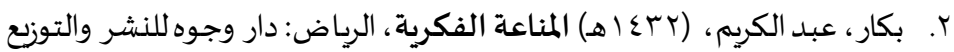
r. الجرجاني، علي محمد السيد، (د.ت) التعريفات، تحقيق: محمد صبديق المنشاوي. القاهرة: دار الفضيلة للنشر والتوزع والتصيدير

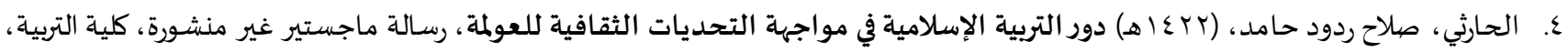
جامعة أم القرى، مكة المكرمة، المملكة العربية السعودياة

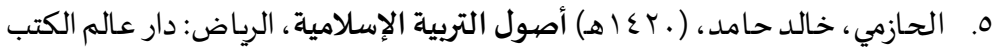

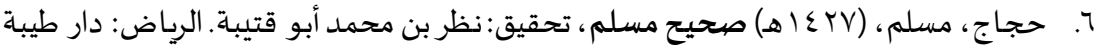

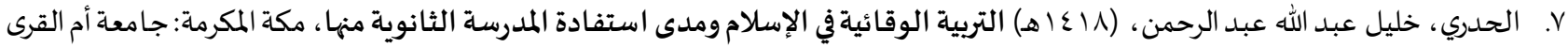

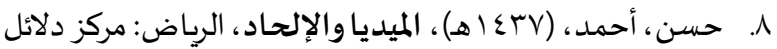

9.

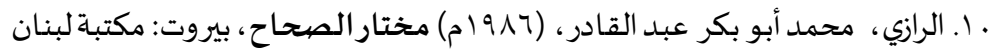

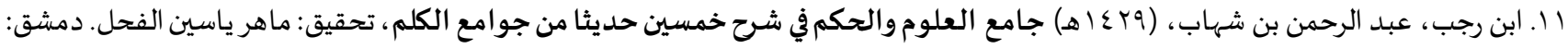
دار ابن كثير

r ا. الزحيلي، محمد مصطفى، (r . ع أهـ) وسـائل الإثبات في الشريعة الإسلامية، دمشق: مكتبة دار البيان

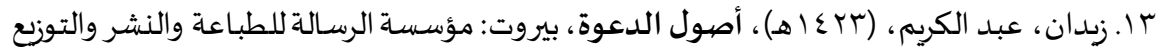

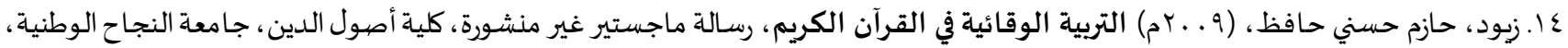
نابلس، فلسطين 0 1. سابق، السيد، (د.ت) ، العقائد الإسلامية، بيروت: دار الكتاب العربي

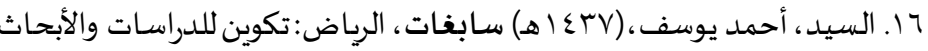

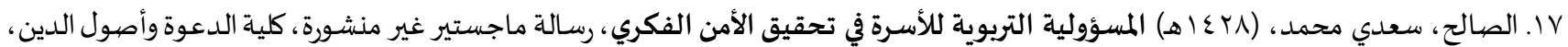
الجامعة الإسلامية بالمدينة المنورة، المدينة المنورة، المملكة العربية السعودية

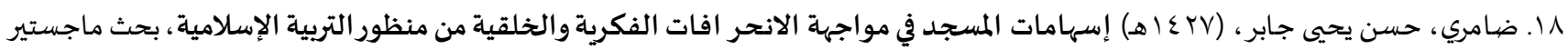
غير منشور، كلية التربية، جامعة أم القرى، مكة المكرمة، المملكة العربية السعودية

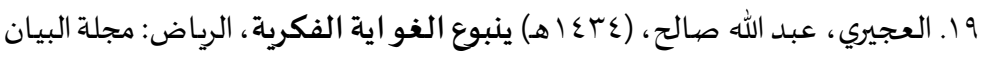

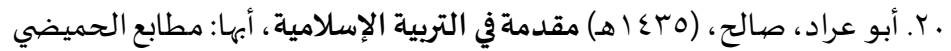

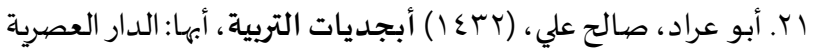

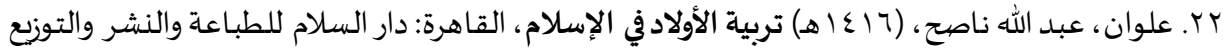

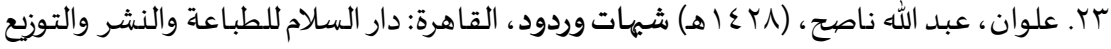

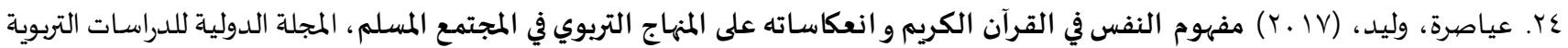


ه r. القرشي، عبد الله بن محمد، (ع اع أهـ) كتاب اليقين "مجموعة رسائل ابن أبي الدنيا"، تحقيق: مصطفى عبد القادر عطا. بيروت: مؤسسة الكتب الثقافية

7 ب. القرضاوي، يوسف، ،د.ت) الإيمان والحياة. د.م rV

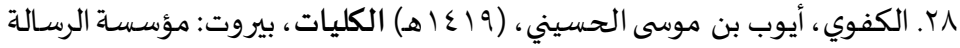

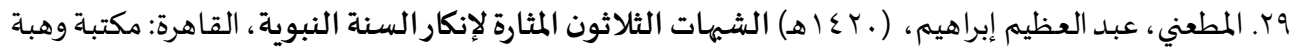

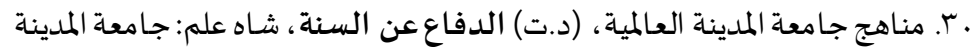

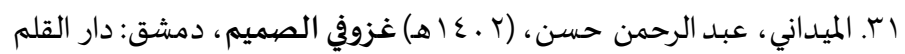

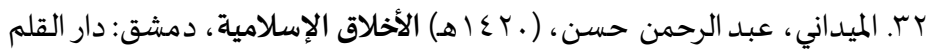

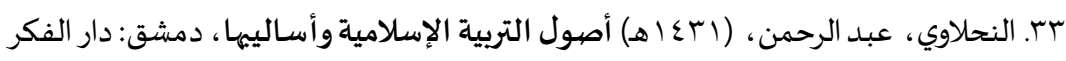

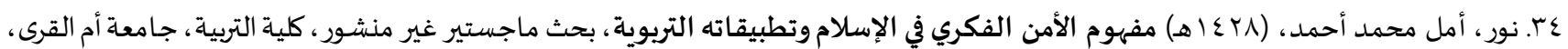

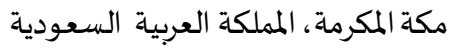




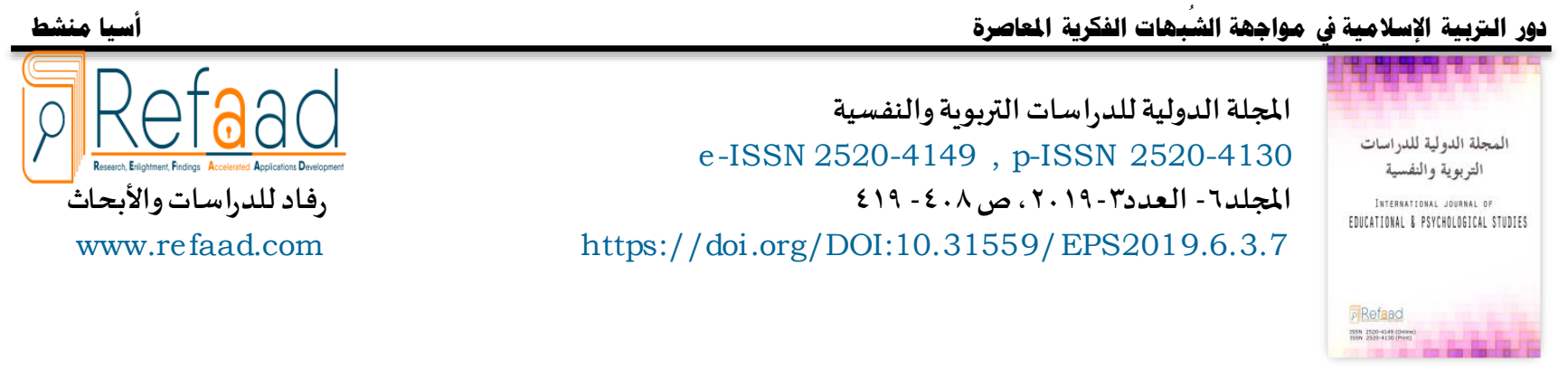

\title{
The role of Islamic Education in the Face of Contemporary Intellectual Su spicions
}

\author{
Asia Hussein Menshet \\ PhD student in the fundamentals of education Al Qussaim university, Kingdom of Saudi Arabia \\ phd.ah40@gmail.com
}

Received Date: 21/4/2019

Accepted Date: 14/5/2019

\begin{abstract}
What is going on in the orbit of contemporary life of events and what is motivated by the scientific progress of the attention of people to the West, which was born to many individuals of intellectual problems and inherited suspicions about the entity of the Islamic religion, this research came to know the role that can be played by Islamic education in the face of suspicions The objective of the study was to identify the meaning of the suspicion and its causes and the role that Islamic education can play. The analytical descriptive approach was used to collect and analyze the data. The research concluded that a number of the results are that Islamic education has a great role and responsibility for preaching Mei in the face of contemporary intellectual suspicions, and can play a preventive role in advance for the preservation and maintenance of Islamic doctrines of the strife raised around the origins of Islam, and that the various means and scientific programs proposed in the arena resonate significantly in the confrontation and prevention and treatment, and promote certainty based on the faith education that should All that breeders.
\end{abstract}

Keywords: Islamic education, Suspicions

\section{References:}

- Ạlqrận Ạlkrym

[1] 'lwạn. ‘bd Ạllh Nạsḥ, Trbyë Ạlạ̉wlạd Fy Ạląslạm, Ạlqạhrh: Dạr Ạlslạm Llṭbậh Wạlnsh̆r Wạltwzyc, (1416h)

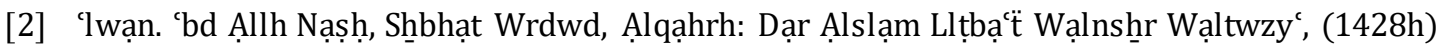

[3] Ạlcjyry. 'bd Ạllh Ș̣alh, Ynbw Ạlghwwạyh Ạlfkryh, Ạlryạd: Mjlë Ạlbyạn, (1434h)

[4] ̣̉bw 'rạd. Șạlḥ, Mqdmë Fy Ạltrbyh Ạlạslạmyh, Ạ̉bhạ: Mțạb` Ạlḥmyḍ̂, (1435h)

[5] Ạ̉bw 'rạd. Ṣạlh 'ly, Ạ̉bjdyạt Ạltrbyh, Ạ̉bhạ: Ạldạr Ạl'ṣryh, (1432h)

[6] 'yạşra. Wlyd, Mfhwm Ạlnfs Fy Ạlqrận Ạlkrym Wạn'kạsạth 'la Ạlmnhạj Ạltrbwy Fy Ạlmjtm Ạlmslm, Ạlmjlh Ạldwlyh Lldrạsạt Ạltrbwyh Wạlnfsyh, Ạlmjld Ạlạ̉wl, Ạl'dd Ạlthِạlthِ(2017), https://doi.org/10.12816/0043565

[7] Bkạr. 'bd Ạlkrym, Ạlmnạch Ạlfkryh, Ạlryạd: Dạr Wjwh Llnsḥr Wạltwzy', (1432h)

[8] Dạmry. Ḥsn Yhyy Jạbr, Ashạmạt Ạlmsjd Fy Mwạjh̆̈ Ạlạnhrạfạt Ạlfkryh Wạlkhlquyh Mn Mnẓwr Altrbyh

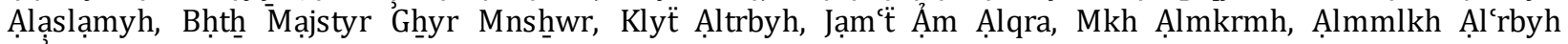
Ạls ${ }^{c} w d y h,(1427 h)$

[9] Ạlhạarthyy. Șlạh Rdwd Hạmd, Dwr Altrbyh Ạlạslạmyh Fy Mwạjhë Ạltḥdyạt Ạlthaqạfyh Ll'wlmh, Rsạlt Mạjstyr

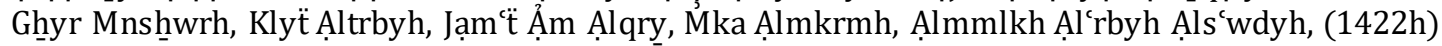

[10] Ạlhạazmy. Khạld Ḥạmd, Ạ̉ṣwl Ạltrbyh Ạlą̧slạmyh, Ạlryạd: Dạr 'ạlm Ạlktb, (1420h) 
[11] Allḥdry. Khlyl ‘bd Ạllh ‘bd Ạlrḥmn, Altrbyh Ạlwqạyyhh Fy Ạląslạm Wmda Ạstfạdh Ạlmdrsh Ạltḥạnwyh Mnhạ, Mka Ạlmkrmh: Jạm‘̈ Ạ̉m Ạlqra, (1418h)

[12] Ḥjạj. Mslm, Ṣhyḥ̣ Mslm, Tḥqyq: Nẓr Bn Mḥmd Ạ̉bw Qtyba. Ạlryạd: Dạr Ṭyba, (1427h)

[13] Ḥsn. Ạ̉hmmd, Ạlmydyạ Wạlą̧ hạad, Ạlryạd: Mrkz Dlạỷl, (1437h)

[14] Ḥsyn. Mḥmd Ạlkhḍr, Ạlạihạd Ạ̉sbạbh Ṭbậ̉h Mfạsdh Ạ̉sbạb Ẓhwrh 'lạjh, Ạlkwyt: Mktbë Ạbn Tymya, (1406h)

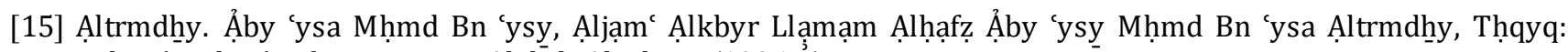
Bshạar 'wạd M'rwf. Byrwt: Dạr Ạlgḥ̂b Ạląslạmy(1996m)

[16] Ạljrạnny. 'ly Mḥmd Ạlsyd, Ạlttryfạt, Tḥqyq: Mḥmd Șdyq Ạlmnshạawy. Ạlqạhrh: Dạr Ạlfḍylh Llnshnr Wạltwzyc Wạltșdyr

[17] Ạlkfwy. Ảywb Bn Mwsa Ạlḥsyny, Alklyạt, Byrwt: Mw̉ssë Ạlrsạlh, (1419h)

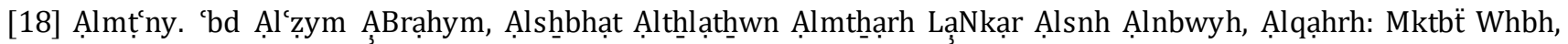
(1420h)

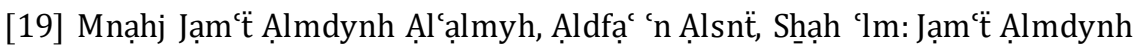

[20] Ạlmydạny. 'bd Ạlrḥmn Ḥsn, Ghnzw Fy Ạlșmym, Dmshoq: Dạr Ạlqlm, (1402h)

[21] Ạlmydạny. 'bd Ạlrḥmn Ḥsn, Ạlạ̉khַlạq Ạlạslạmyh, Dmsḥq: Dạr Ạlqlm, (1420h)

[22] Ạlnḥlạwy. 'bd Ạlrḥmn, Ạ̉ṣwl Ạltrbyh Ạlạslạmyh Wạ̉sạlybhạ, Dmshnq: Dạr Ạlfkr, (1431h)

[23] Nwr. Ạ̉ml Mḥmd Ạ̉hmd, Mfhwm Ạlạ̉mn Ạlfkry Fy Ạlạslạm Wtṭbyqạth Ạltrbwyh, Bḥth Mạjstyr Ghyr Mnshwwr, Klyẗ Ạltrbyh, Jạm‘̈ Ạ̉m Ạlqra, Mkh Ạlmkrmh, Ạlmmlkh Ạl'rbyh Ạls'wdyh, (1428h)

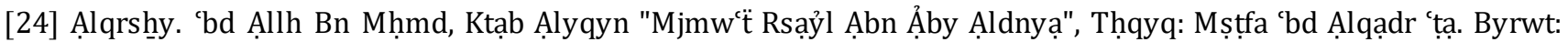
Mw̉ssï Ạlktb Ạlthֵqạfyh, (1414h)

[25] Ạlqrḍạwy. Ywsf, Ạlą̧mạn Wạlhỵạh, D.M

[26] Qțb. Mḥmd, Shbhạat Ḥwl Ạląsslạm, Ạlqạhrh: Dạr Ạlsḥrwq, (1413h)

[27] Ạlrạzy. Mḥmd Ạ̉bw Bkr 'bd Ạlqạdr, Mkḥtạr Ạlṣḥạḥ, Byrwt: Mktbë Lbnạn, (1986m)

[28] Ạbn Rjb. 'bd Ạlrḥmn Bn Shhạb, Jạm` Ạl'lwm Wạlḥkm Fy Shhrh Khmsyn Ḥdytḥạ Mn Jwạm Ạlklm, Tḥqyq: Mạhr Yạsyn Ạlfḥl. Dmsḥq: Dạr Ạbn Ktȟyr, (1429h)

[29] Sạbq. Ạlsyd, Ạl'qậ̉d Ạlạslạmyh, Byrwt: Dạr Ạlktạb Ạl'rby

[30] Alsạlḥ. S`dy Mhmd, Ạlmsw̉wlyẗ Ạltrbwyë Llạ̉srë Fy Thqyq Ạlạ̉mn Ạlfkry, Rsạlẗ Mạjstyr Ghyr Mnshwrh, Klÿ̈ Ạld'wh Wạ̉ṣwl Ạldyn, Ạljạm‘h Ạlạjslạmyh Bạlmdynh Ạlmnwrh, Ạlmdynh Ạlmnwrh, Ạlmmlkh Ạl'rbyh Ạls'wdyh, (1428h)

[31] Ạlsyd. Ạ̉ḥmd Ywsf, Sạbghạạt, Ạlryạd: Tkwyn Lldrạsạt Wạlạ̉bḥạthِ, (1437h)

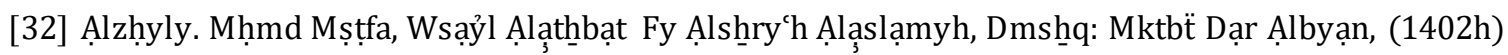

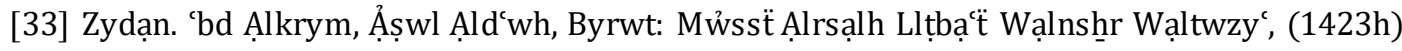

[34] Zywd. Hạzm Hịny Hạfż, Ạltrbyh Ạlwqậ̉yh Fy Ạlqrận Ạlkrym, Rsạlẗ Mạjstyr Ghnyr Mnshowrh, Klyë Ạ̉ṣl Ạldyn, Jạm ‘̈ Ạlnjạh Ạlwṭnyh, Nạbls, Flsțn, (2009m). 